\title{
VIDA EM SERVIÇO DE ROLAMENTOS AUTOCOMPENSADORES DE ROLOS VEDADOS APLICADOS EM ROLOS SECADORES DE LINHA DE ESTANHAMENTO ELETROLÍTICO DE CHAPAS *
}

\author{
Fabricio Sartori Trani ${ }^{1}$ \\ Rogério Martelli² \\ Luiz Carlos de Paula ${ }^{3}$ \\ Bruno Avelino de Souza Silva ${ }^{4}$
}

\begin{abstract}
Resumo
Os mancais de rolamento dos rolos secadores da linha de estanhamento eletrolítico da CSN são expostos a severa contaminação por água e ácido sulfúrico. O tempo médio entre falhas (MTBF) de cada rolamento da linha é de apenas 30 dias. A CSN aceitou realização de teste com um par de rolamentos autocompensadores de rolos vedados que foram montados em um rolo, com a supervisão da SKF. Os rolamentos do teste operaram por mais de 150 dias, apresentando sobrevida superior a $400 \%$ até o momento, sendo que ainda continuam em operação. Há cerca de 60 rolamentos operando simultaneamente na linha, sendo que a solução poderá ser replicada para os demais pontos, aumentando a vida em serviço dos rolamentos e reduzindo custos de manutenção.
\end{abstract}

Palavras-chave: Rolamentos; Vedações; Vida; Contaminação

\begin{abstract}
SERVICE LIFE FOR SEALED SPHERICAL ROLLER BEARINGS
Abstract

The rolling bearings of the drying rolls of CSN's electrolytic tinning line are exposed to severe contamination by water and sulfuric acid. The mean time between failures (MTBF) of each bearing of the line is only 30 days. CSN has accepted to perform a test with a pair of sealed spherical roller bearings that were mounted in one roll, with the supervision of SKF. The bearings of the test have operated for more than 150 days, presenting $400 \%$ of extra life so far, and are still in operation. There are about 60 bearings operating simultaneously in the line and the solution can be replicated to the other positions, increasing the service life of the bearings and reducing maintenance costs.
\end{abstract}

Keywords: Bearings; Seals; Life; Contamination

1 Engenharia Mecânica - FEl, Engenheiro Mecânico, Engenheiro de Aplicação PL, Engenharia de Aplicação, SKF do Brasil, Cajamar, SP, Brasil.

2 Engenharia Mecânica - UMC, Engenheiro Mecânico, Engenheiro de Aplicação PL, Engenharia de Aplicação, SKF do Brasil, Cajamar, SP, Brasil.

3 Técnico em Mecânica - Escola Técnica Duque de Caxias, Técnico Mecânico, Técnico Montador PL, Engenharia de Campo, SKF do Brasil, Cajamar, SP, Brasil.

4 Engenharia Mecânica - UNIFOA, Engenheiro Mecânico, Engenheiro de Manutenção PL, DEPRO/GGFM/GEE, Companhia Siderúrgica Nacional, Volta Redonda, RJ, Brasil. 


\section{INTRODUÇÃO}

Os dois rolamentos avaliados no teste operaram por duas campanhas. A primeira campanha iniciou-se no dia 26/08/2016 e os rolamentos operaram por 95 dias. Após a primeira campanha, os rolamentos foram desmontados para inspeção visual e foram aprovados. A segunda campanha teve então início em 10/01/2017 e os rolamentos operaram por 60 dias. Após a segunda campanha, ambos foram inspecionados e aprovados novamente. Atualmente, os rolamentos já estão operando na terceira campanha. A Figura 1 ilustra um rolo secador com um rolamento montado em cada extremidade e a Figura 2 mostra a severidade da incidência de água nos mancais.

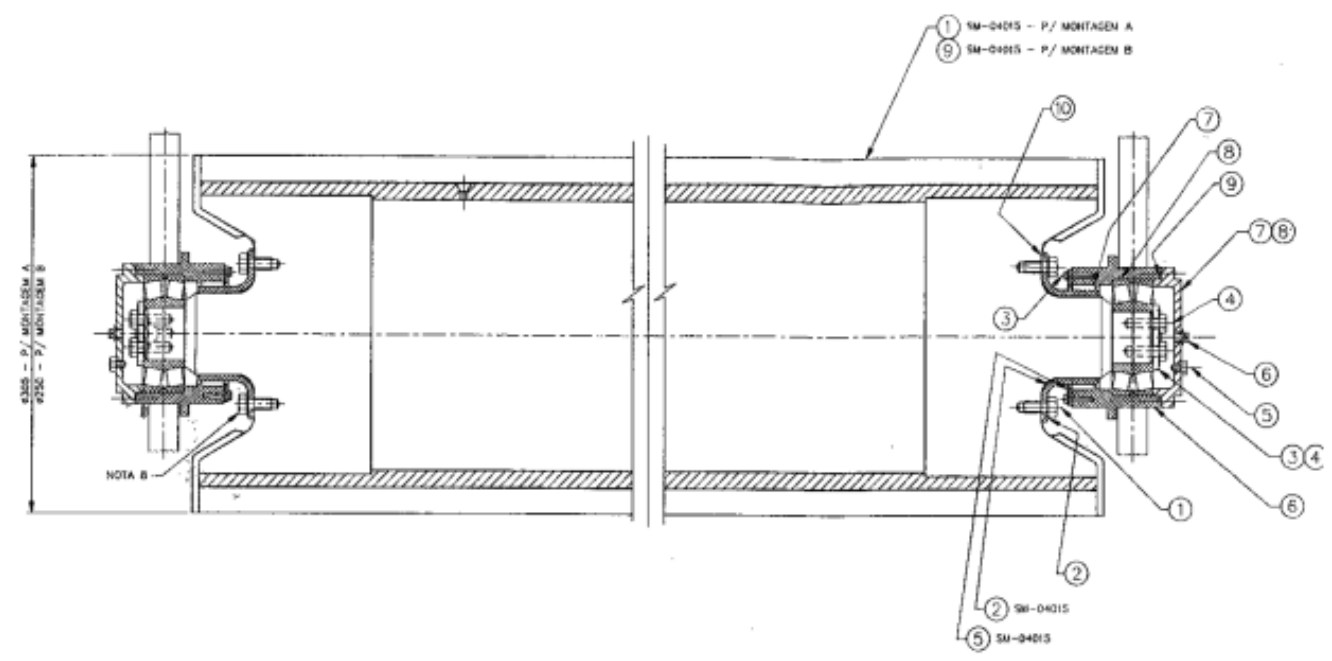

Figura 1. Desenho do rolo secador.

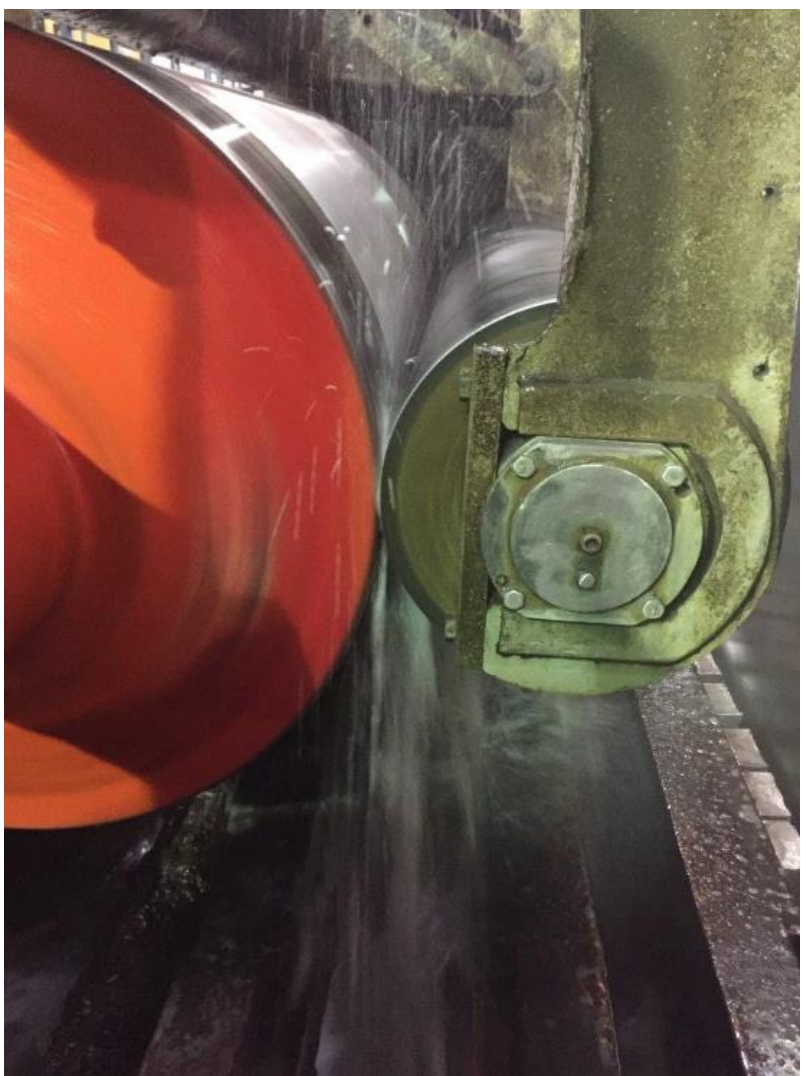

Figura 2. Incidência de água nos mancais. 


\subsection{Designação dos Rolamentos}

Os dois rolamentos SKF são de designação BS2-2309-2CS/VT143, conforme mostrado na Figura 3. A designação principal (BS2-2309) difere do padrão seguido pela maioria dos fabricantes de rolamentos (22309), pois a largura do rolamento é aumentada em $6 \mathrm{~mm}$ para poder acomodar as vedações.

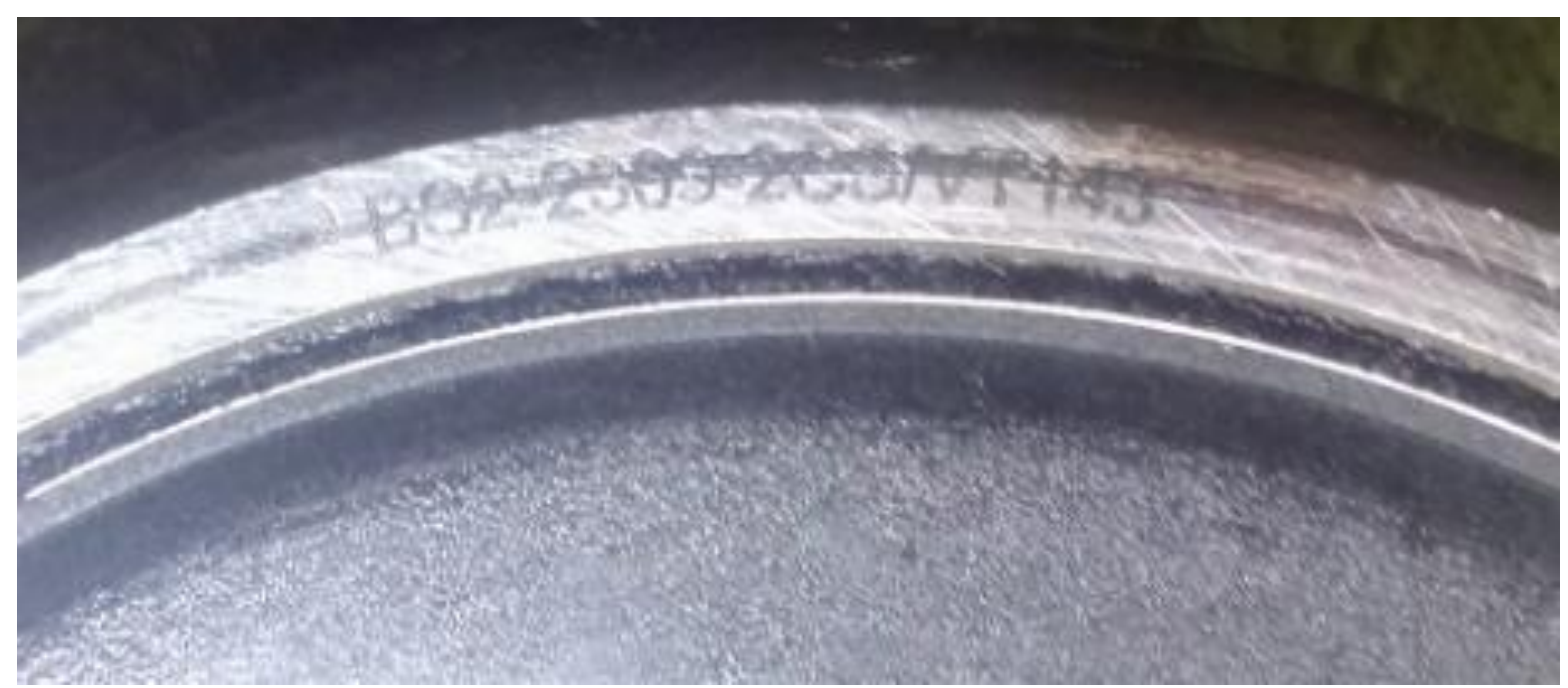

Figura 3. Designação dos rolamentos.

\subsection{Objetivo}

O objetivo deste trabalho é apresentar o resultado do aumento da vida em serviço atual com a aplicação de rolamentos autocompensadores de rolos vedados. Em adição, serão apresentadas as características técnicas destes rolamentos, bem como o conceito SKF tríplice barreira. 


\section{MATERIAIS E MÉTODOS}

\subsection{Dados da Aplicação}

Os dados da aplicação constam na Tabela 1:

Tabela 1. Dados da aplicação.

\begin{tabular}{|l|l|}
\hline Aplicação & $\begin{array}{l}\text { Rolos secadores da linha de estanhamento eletrolítico } \\
\text { de chapas }\end{array}$ \\
\hline Rolamentos & $\begin{array}{l}\text { Fabricante: SKF } \\
\text { Designação: BS2-2309-2CS/VT143 } \\
\text { Quantidade: 2 }\end{array}$ \\
\hline Ambiente & Severo (umidade) \\
\hline Lubrificação & $\begin{array}{l}\text { Lubrificado para vida } \\
\text { Graxa à escolha para conceito Tríplice Barreira }\end{array}$ \\
\hline Rotação & 764 rpm \\
\hline Temperatura & 60C \\
\hline $\begin{array}{l}\text { Vedações externas } \\
\text { (somente primeira } \\
\text { campanha) }\end{array}$ & $\begin{array}{l}\text { Fabricante: SKF } \\
\text { Designação: 80x100x10 HMS5 V } \\
\text { Quantidade: 4 (em tandem para reter contaminantes) }\end{array}$ \\
\hline Ajustes & $\begin{array}{l}\text { Eixo: m6 } \\
\text { Caixa: H6 }\end{array}$ \\
\hline
\end{tabular}

\subsection{Conceito SKF Tríplice Barreira}

O conceito SKF Tríplice Barreira, ilustrado na Figura 4, tem a finalidade de integrar vedações adicionais ao sistema, provendo maior proteção ao rolamento contra o ingresso de contaminantes. As três barreiras são: vedações externas, graxa (não utilizada como lubrificante e sim como vedante) e vedações do rolamento.

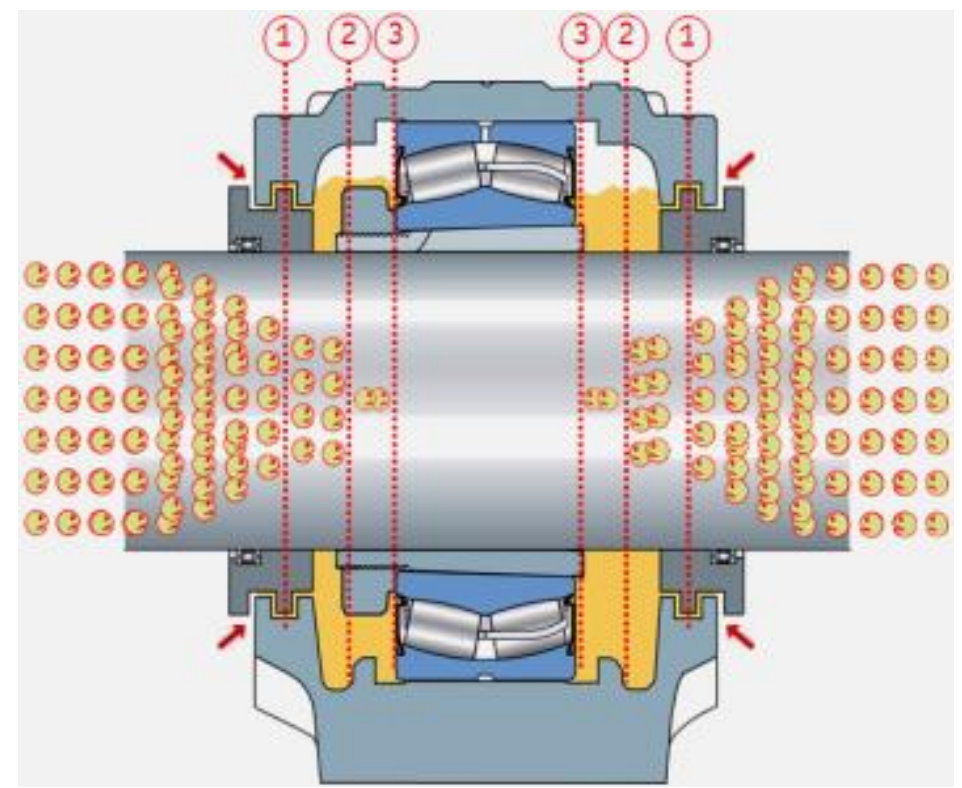

Figura 4. Conceito SKF Tríplice barreira. 
O conceito Tríplice Barreira foi colocado em prática no ato da montagem, conforme ilustrado pelas Figuras 5 a 10, que ilustram todo o procedimento.

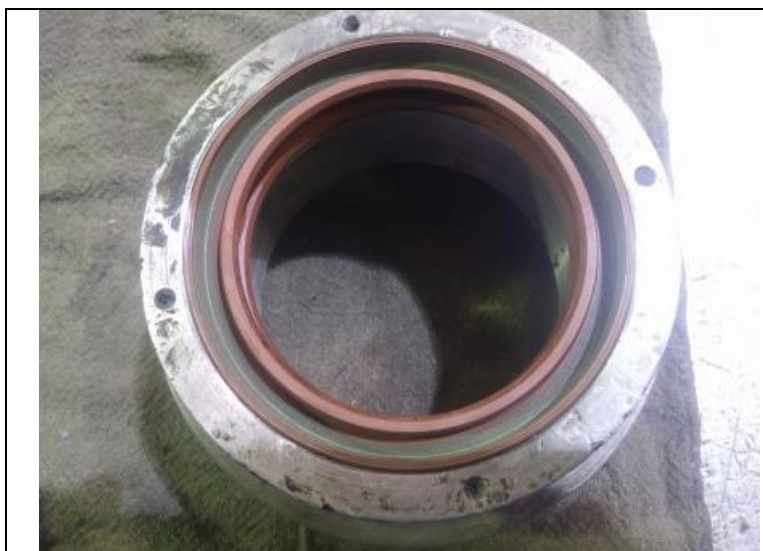

Figura 5. Montagem das vedações externas (1 a barreira).

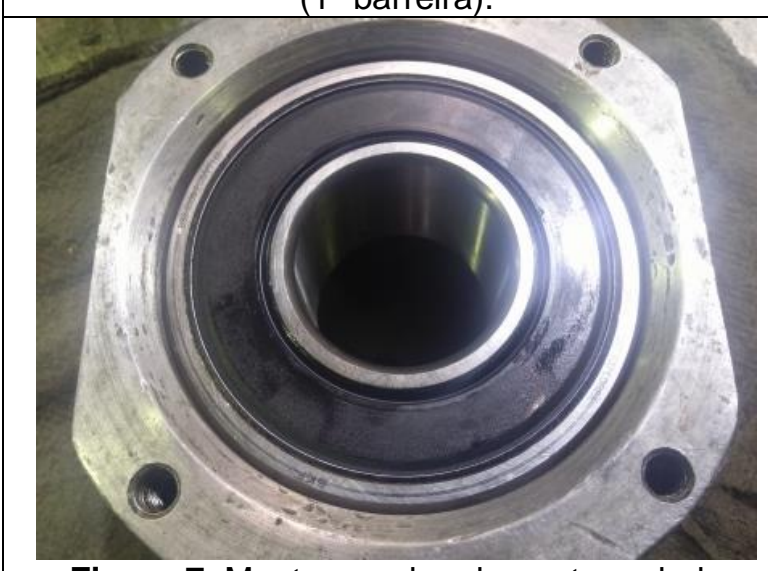

Figura 7. Montagem do rolamento vedado ( $2^{\mathrm{a}}$ barreira).

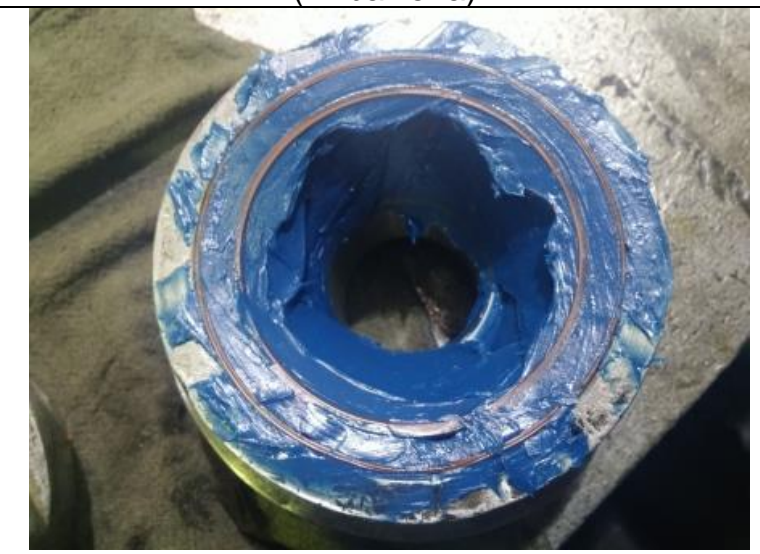

Figura 9. Preenchimento de $80 \%$ do espaço da caixa com graxa ( $3^{\mathrm{a}}$ barreira).

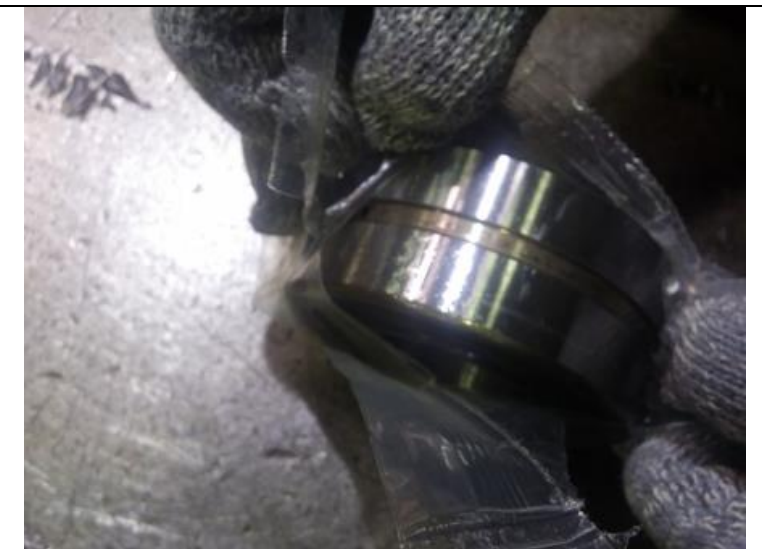

Figura 6. Abertura da embalagem do rolamento no momento da montagem.

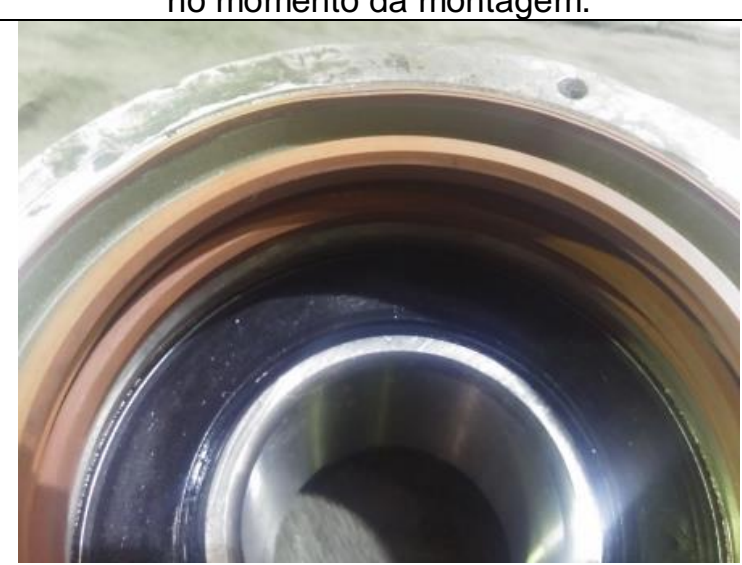

Figura 8. Vedações e rolamento montados.

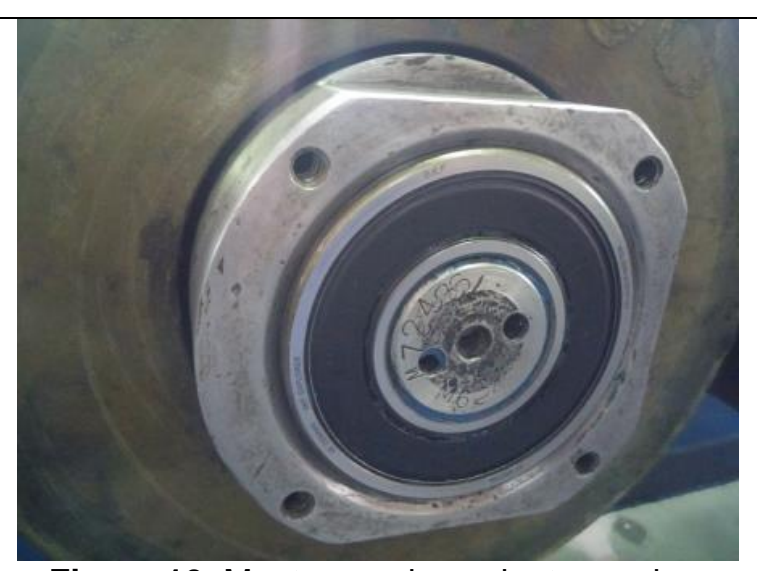

Figura 10. Montagem do conjunto no eixo.

\subsection{Características do Rolamento Vedado}

Um rolamento autocompensador de rolos vedado possui vedações de contato em ambos os lados (sufixo 2CS), que evitam a entrada de contaminantes e retêm a graxa, conforme figura 11. 

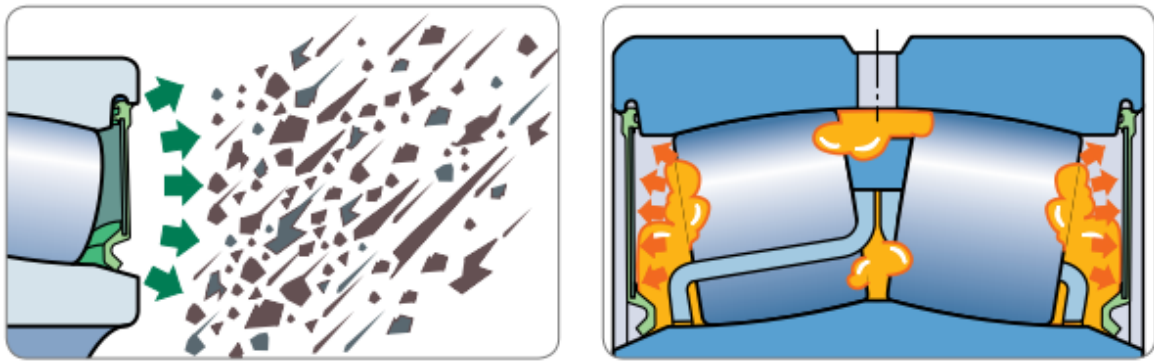

Figura 11. Vedações para evitar a entrada de contaminantes e reter a graxa.

Além das vedações, o projeto vedado contempla também graxa de fábrica (sufixo VT143). Na maioria dos casos, a relubrificação é desnecessária, porém é possível introduzir carga adicional de graxa pelos furos do anel externo (W33) para as aplicações mais críticas, conforme destacado na Figura 12.
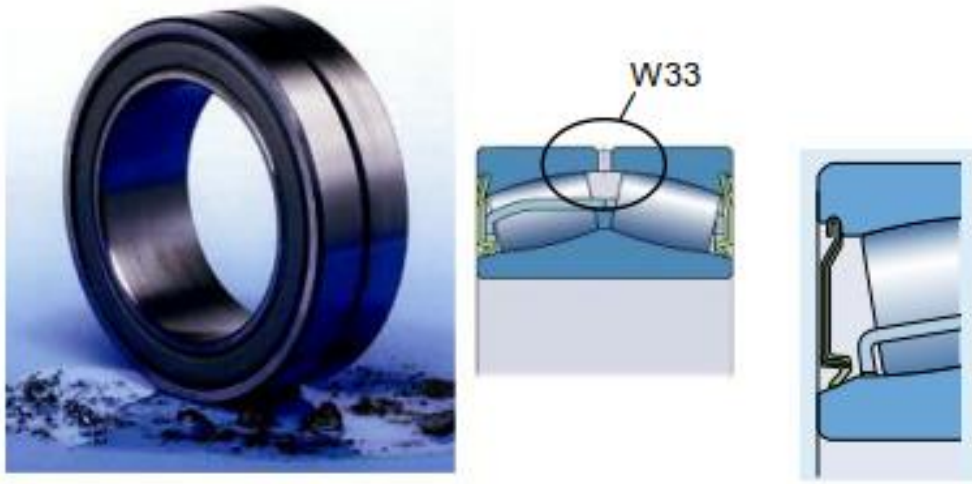

Figura 12. Furos para relubrificação (W33) e perfil da vedação de contato.

Para o caso em estudo, como a caixa de mancal não é preparada para fornecer lubrificante através do anel externo do rolamento, considera-se que o rolamento é lubrificado para vida. Para as condições da aplicação, o ábaco da Figura 13 indica uma vida $L_{01}$ da graxa de 25.000 horas de operação, portanto a vida do rolamento será limitada a este valor, que é muito superior à vida média atual (720 horas).

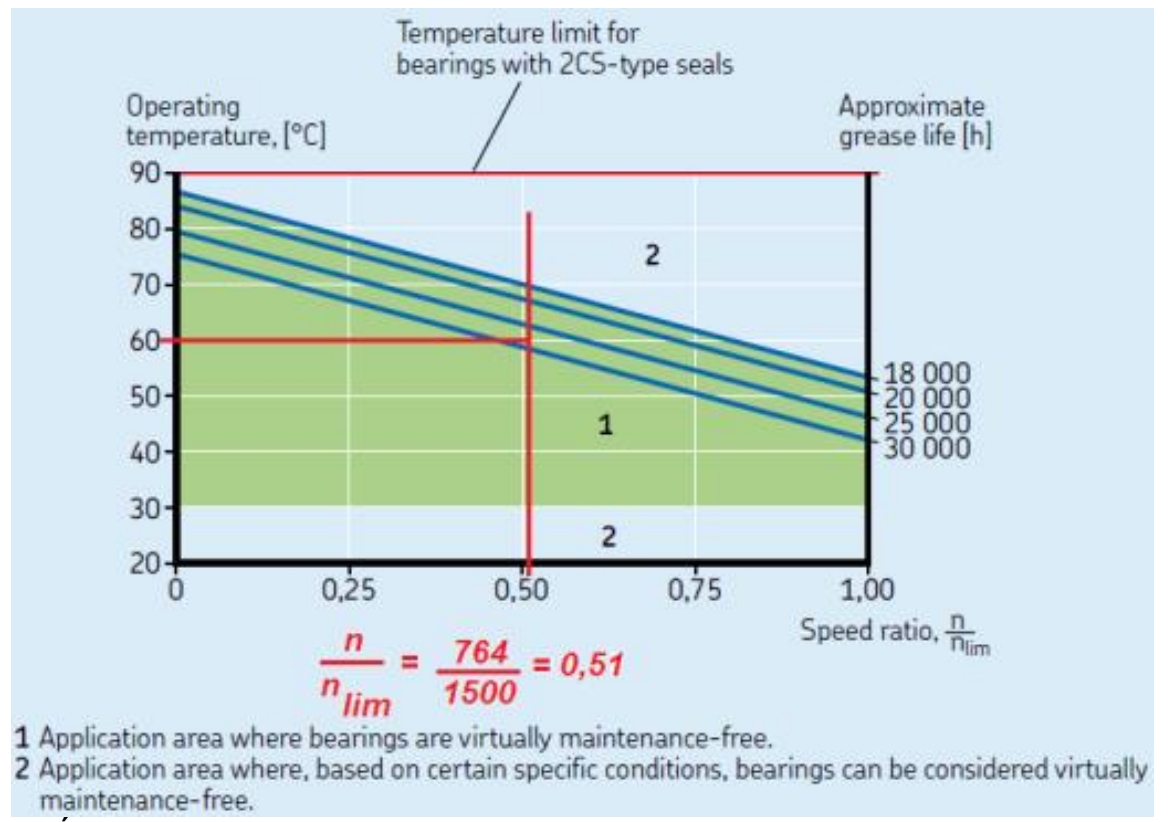

Figura 13. Ábaco de vida da graxa para rolamentos autocompensadores de rolos vedados. 


\section{RESULTADOS E DISCUSSÃO}

\subsection{Primeira Inspeção}

Após a primeira campanha, os rolamentos foram inspecionados. As vedações de um deles foram removidas para permitir a análise dos componentes internos. As vedações são deformadas durante a remoção, portanto este rolamento foi montado sem elas para rodar a segunda campanha. Como todos os componentes internos do primeiro rolamento estavam em bom estado visual, o segundo rolamento permaneceu com as vedações para rodar a segunda campanha. As figuras 14 a 19 mostram o resultado da primeira inspeção.

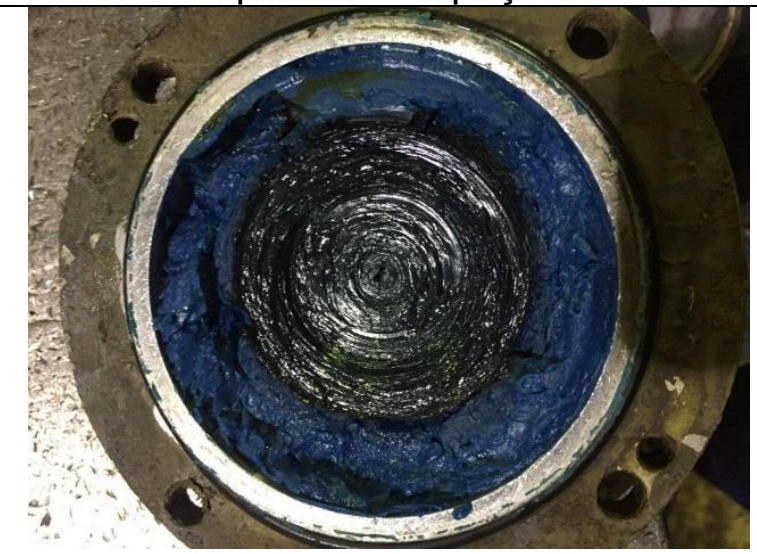

Figura 14. Aspecto da graxa.

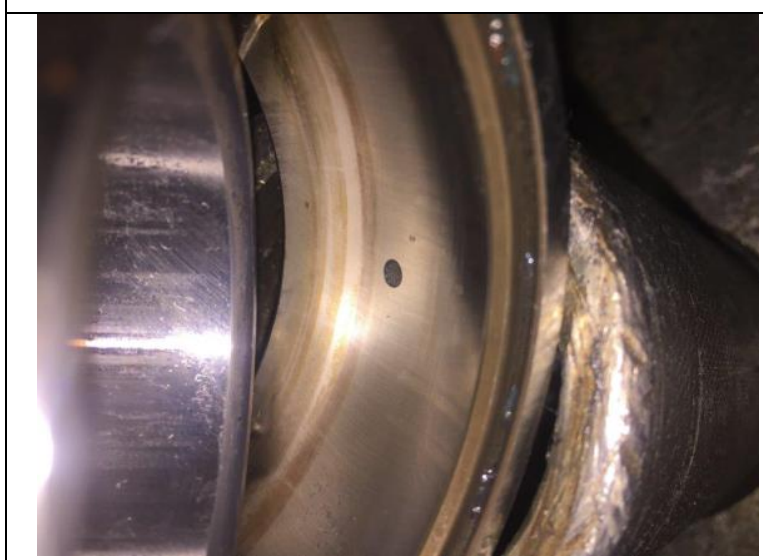

Figura 16. Inspeção das pistas do anel externo.

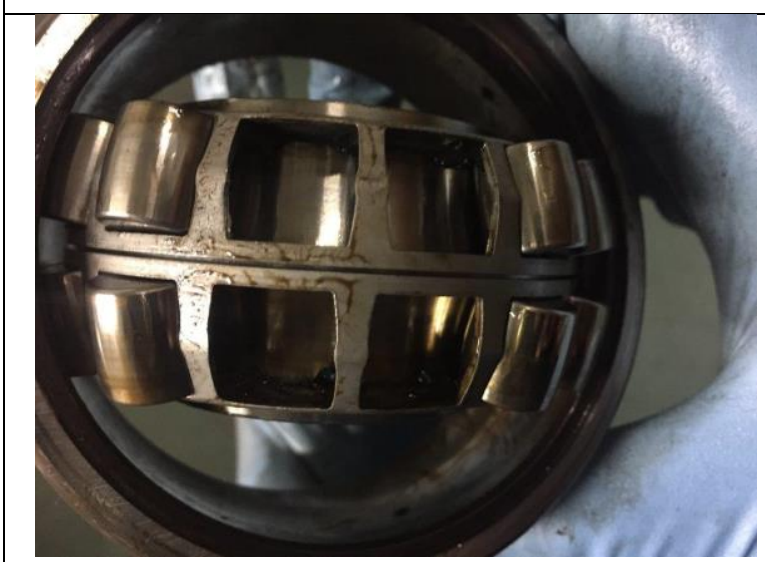

Figura 18. Inspeção das pistas do anel interno.

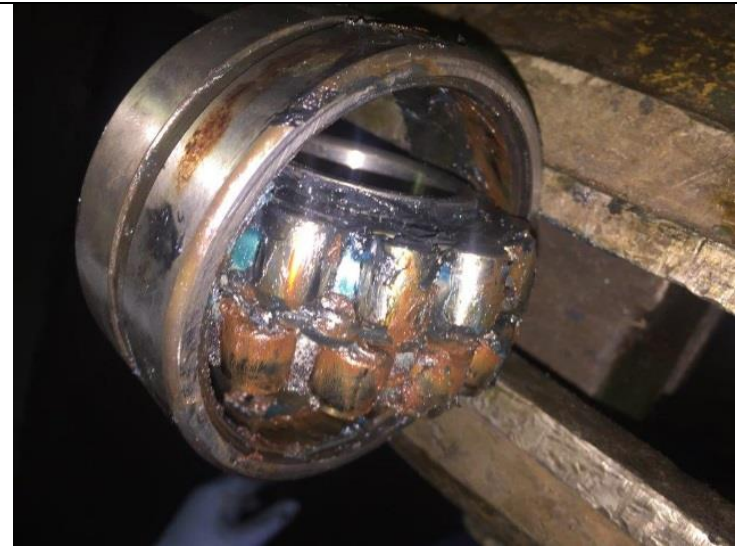

Figura 15. Aspecto do rolamento.

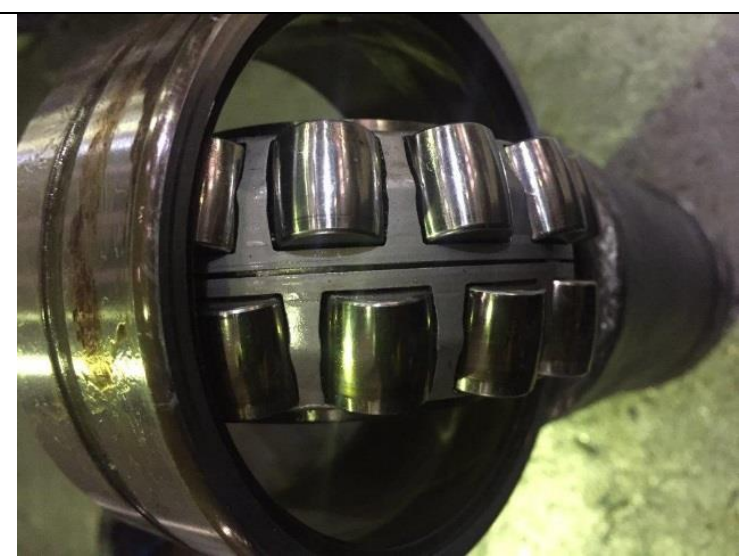

Figura 17. Inspeção dos elementos rolantes e gaiola.

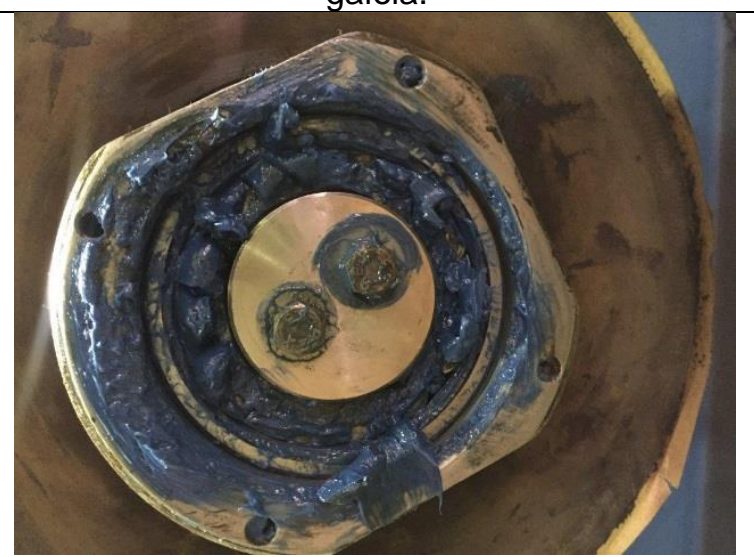

Figura 19. Relubrificação para operar a segunda campanha. 


\subsection{Segunda Inspeção}

Após a segunda campanha, os rolamentos foram inspecionados novamente e mais uma vez apresentaram bom estado visual, com marcas normais de trabalho. $O$ outro rolamento permaneceu com as vedações para rodar a terceira campanha (atual). Foram encontradas marcas de corrosão de contato no diâmetro externo e furo, que podem ser decorrentes dos repetitivos processos de montagem e desmontagem dos rolamentos. As figuras 20 a 25 mostram o resultado da segunda inspeção.

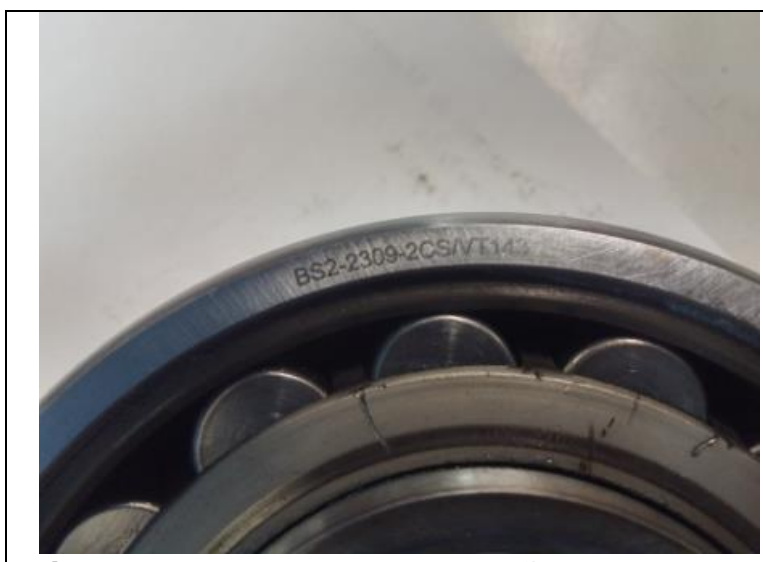

Figura 20. Detalhe da designação do rolamento aberto.

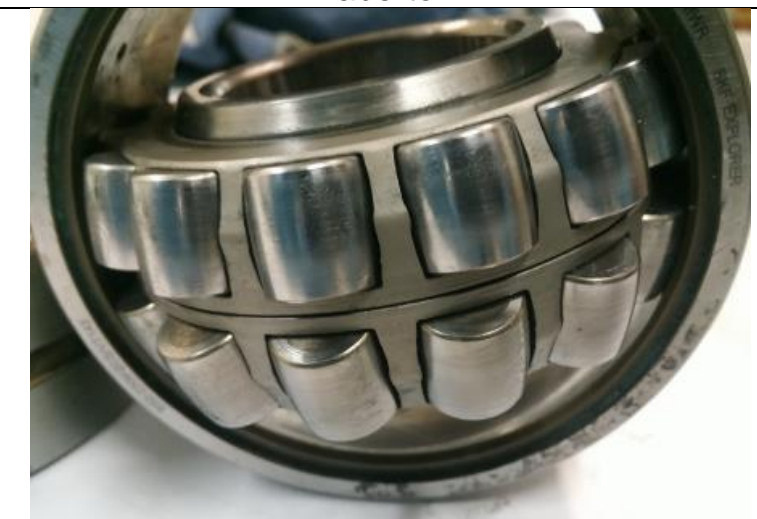

Figura 22. Inspeção dos elementos rolantes e gaiola.

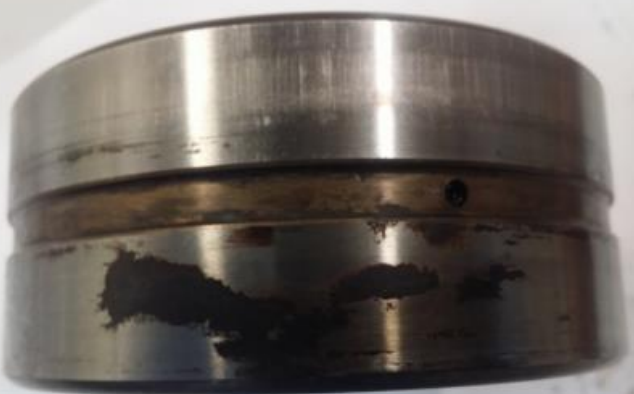

Figura 24. Rolamento com corrosão de contato no diâmetro externo.

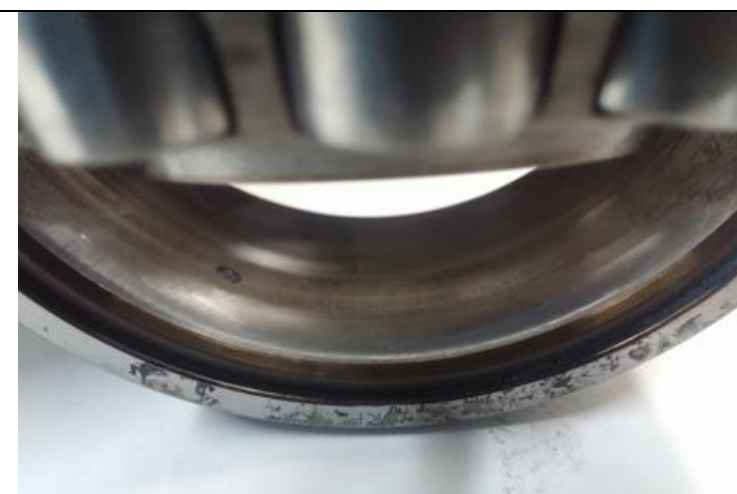

Figura 21. Inspeção das pistas do anel externo.

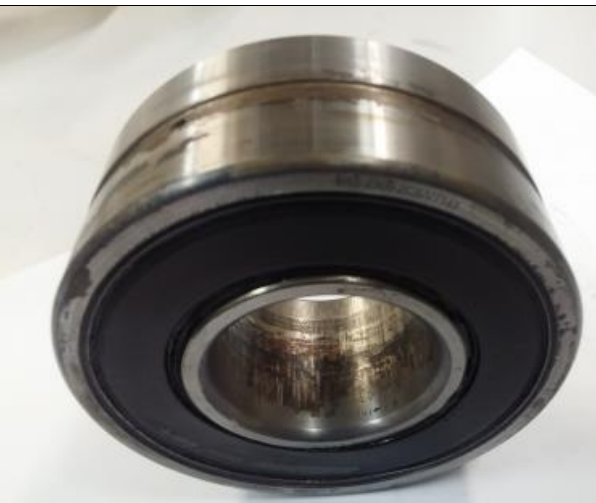

Figura 23. Inspeção do rolamento vedado.

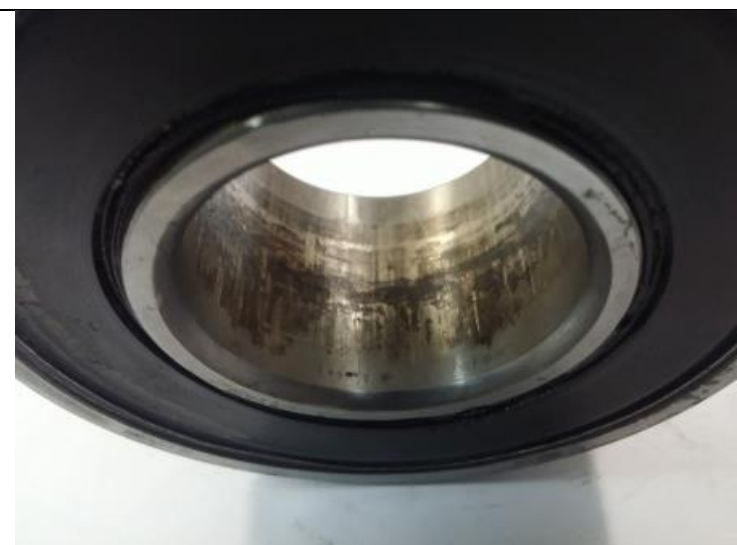

Figura 25. Rolamento com corrosão de contato no furo. 


\subsection{Benefícios dos Rolamentos SKF autocompensadores de rolos vedados}

- Aumento da vida em serviço dos rolamentos em ambientes contaminados, exemplificado na Figura 26 (fator de contaminação $\eta_{c}=0,1-0,4$ para rolamentos abertos, linha vermelha; $\eta_{c}=0,6-0,9$ para rolamentos vedados, linha verde);

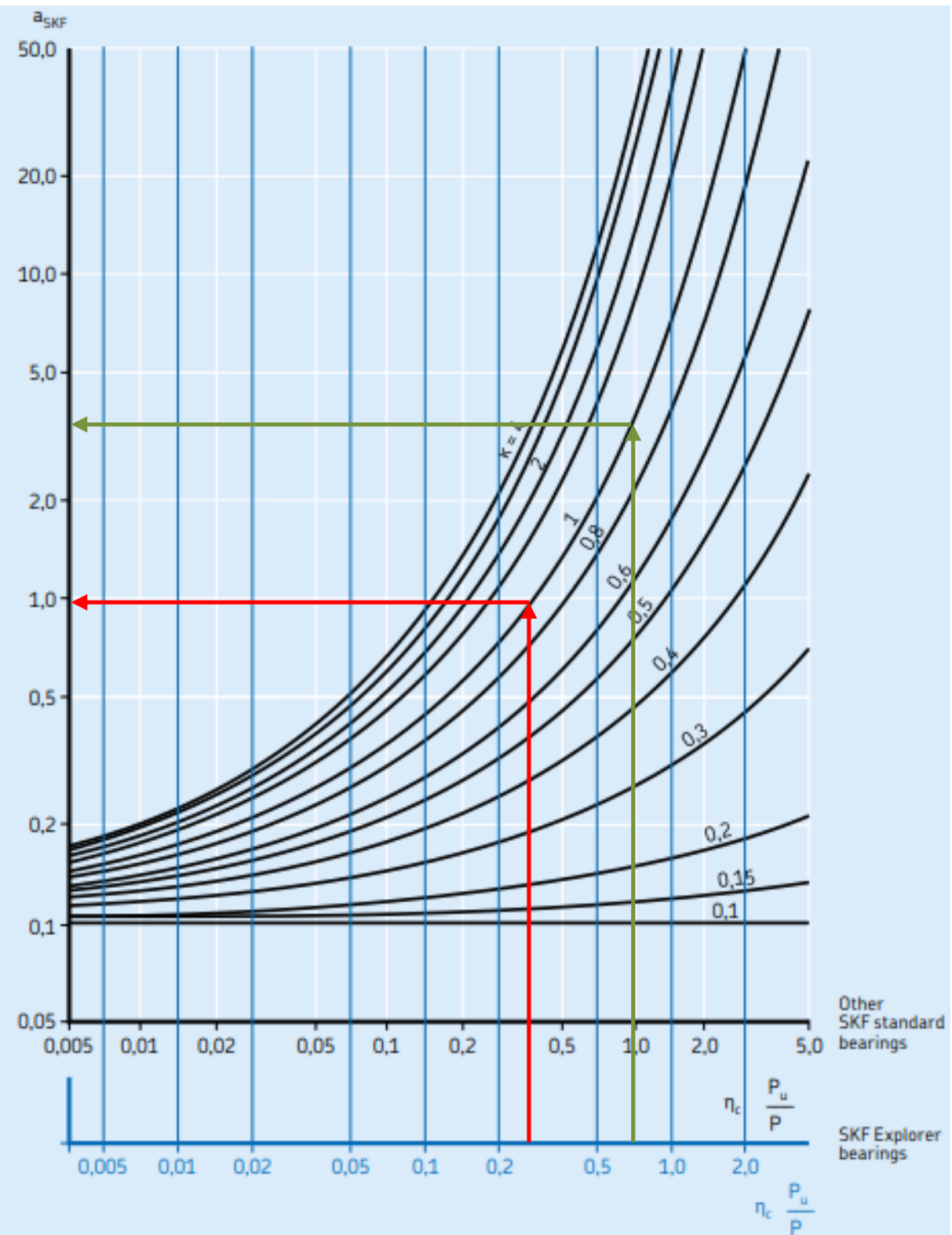

Figura 26. Ábaco do fator askf para rolamentos de rolos, considerado $K=1$ e $P u / P=1$.

- Aumento da confiabilidade do equipamento;

- Redução dos custos de manutenção;

- Redução do consumo de lubrificante;

- Redução de impactos ambientais. 


\section{CONCLUSÃO}

Este estudo apresentou o aumento de desempenho e vida em serviço de rolamentos autocompensadores de rolos vedados, aplicados nos rolos secadores da linha de estanhamento eletrolítico de chapas da CSN. Os dois rolamentos do teste já apresentaram ganho de $400 \%$, sendo que ainda continuam em operação. Mesmo após a segunda inspeção, os rolamentos encontraram-se em bom estado visual, estando aptos a rodar uma terceira campanha. Para efeito comparativo, na condição atual alguns rolamentos falham ainda na primeira campanha, o que atesta o ganho com o uso de rolamentos vedados. Outros benefícios como redução dos custos de manutenção e maior confiabilidade do equipamento também são atingidos.

\section{REFERÊNCIAS}

$1 \quad$ Rolling bearings, PUB BU/P1 10000/2 EN, Agosto 2013.

2 ISO 15243:2004 - Rolling bearings - Damage and failures - Terms, characteristics and causes.

3 Bearing damage and failure analysis, PUB BU/I3 14219 EN, Março 2014.

4 Sealed SKF Explorer spherical roller bearings - Optimum protection against contaminants, downtime and high maintenance costs, PUB BU/P2 10704/l, Abril 2013.

5 Sealed SKF Explorer spherical roller bearings - Protected for superior field performance, PUB BU/P2 15501/2 EN, Fevereiro 2016. 